\title{
A ECONOMIA SOLIDÁRIA COMO DETERMINANTE NA TRAJETÓRIA PROFISSIONAL DE SEUS PARTICIPANTES: UM ESTUDO MULTICASOS NO SETOR DE RECICLAGEM DE UBERLÂNDIA-MG
}

Camila Maria De Oliveira ${ }^{1}$

Amanda Silva Resende Jorge ${ }^{1}$

Márcia Freire De Oliveira ${ }^{1}$

Eduardo Vinícius Gomes Tavares ${ }^{1}$

${ }^{1}$ Universidade Federal de Uberlândia - Faculdade de Gestão e Negócios 


\section{A ECONOMIA SOLIDÁRIA COMO DETERMINANTE NA TRAJETÓRIA PROFISSIONAL DE SEUS PARTICIPANTES: UM ESTUDO MULTICASOS NO SETOR DE RECICLAGEM DE UBERLÂNDIA-MG}

Resumo: Este estudo possui como objetivo analisar o impacto da atuação em Empreendimentos Econômicos Solidários na trajetória profissional de seus participantes. Para isso, foi realizado um estudo de casos múltiplos, qualitativo, no setor de reciclagem de Uberlândia-MG. A coleta de dados aconteceu por meio de entrevistas semiestruturadas realizadas com participantes, gestores e ex-participantes de 5 empreendimentos organizados por catadores de materiais recicláveis. Foram entrevistados ao todo 18 pessoas e os dados colhidos foram analisados por meio da técnica de análise de conteúdo. Os resultados obtidos apontam que, diretamente, esses empreendimentos possibilitam estabilidade financeira, maiores ganhos, autonomia nas decisões referente ao trabalho, acesso a capacitação profissional, além da melhoria de infraestrutura e condições de trabalho. Indiretamente, geram melhorias na qualidade de vida, consciência sobre direitos e deveres e maior acesso a benefícios sociais. Evidencia-se o prazer em trabalhar com material reciclável e a consciência de preservação ambiental por parte dos participantes.

Palavras-chave: Economia Solidária. Trajetória Profissional. Reciclagem.

\section{Introdução}

A urbanização intensa e a mudança no estilo de vida adotado ocasionou uma mudança significativa na quantidade de resíduos gerados enquanto o aumento do nível de desemprego em razão das exigências para o acesso ao mercado de trabalho, restringiu as possibilidades de sobrevivência para significativos grupos sociais (IPESA, 2013). Neste contexto, houve um aumento no número de pessoas que passaram a desempenhar a ação de catadores nas ruas.

No Brasil, segundo Gutberlet (2012), existem cerca de um milhão de catadores que em geral trabalham informalmente, sujeitando-se a riscos de saúde, acidentes e exploração. Eles constituem uma massa de desempregados que não encontram uma vaga no mercado formal de trabalho por inúmeros fatores, geralmente associados a idade, condição social ou baixa escolaridade e devido a isso, essa atividade tem fortes vínculos com níveis extremos de pobreza (IPESA, 2013).

Tais trabalhadores encontram espaço na economia solidária (ES) cujos princípios se baseiam na inclusão socioeconômica, na autogestão, na equidade e na solidariedade. A união em cooperativas os fortalece e os tornam mais independentes, uma vez que esses empreendimentos visam a redução das desigualdades sociais e a transformação social dos

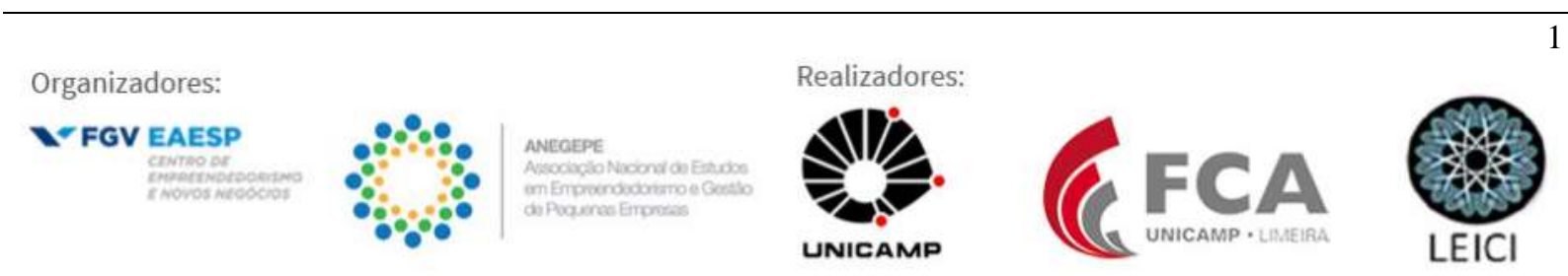


indivíduos marginalizados ou excluídos, por meio da criação de oportunidades de mercado, geração de renda e de valor.

O instrumento de trabalho das cooperativas e associações é a cooperação mútua, a união de seus colaboradores, procurando maximizar, por meio da reciclagem de resíduos, as oportunidades e as mudanças sociais a partir do trabalho solidário ao mesmo tempo que contribuem para a redução de resíduos e a preservação do meio ambiente. Para Tremblay e Gutberlet (2012), esses indivíduos reconhecem a força que ganham a partir da ação coletiva.

Os catadores possuem grande importância junto ao poder público de três maneiras: (1) são os principais agentes do plano de gerenciamento da coleta seletiva; (2) a diminuição da disposição dos resíduos deve ser feita pelo estabelecimento de pré-seleção (segregação, triagem, condicionamento e venda), função executada pelos catadores; e (3) o reconhecimento e valorização dos catadores e sua inclusão só podem ser realizados por meio da participação ativa da categoria (IPESA, 2013).

A partir destes princípios, a presente pesquisa procura responder a seguinte questão: Como a atuação em empreendimentos econômicos solidários (EES) de reciclagem impacta na trajetória profissional de seus participantes? Visando responder esta pergunta, o objetivo geral deste trabalho é analisar o impacto da atuação em EES na trajetória profissional de seus participantes. Mais especificamente buscou-se comparar a situação profissional e a qualidade de vida dos participantes antes, durante e depois da passagem pelos EES, assim como verificar a perspectiva de futuro dos participantes.

A estrutura deste trabalho está composta por uma (i) breve introdução sobre o contexto em que a pesquisa se aplica, (ii) um referencial teórico decorrendo sobre a economia solidária, o sistema de cooperativismo e o impacto na inclusão social e profissional, (iii) a metodologia, (iv) os resultados e discussões e por fim, (v) as conclusões finais.

\section{Referencial Teórico}

\subsection{Economia Solidária}

Ao longo da história, a sociedade foi construída sobre preceitos geradores de grandes contradições, o que coloca em risco a sustentabilidade do planeta seja em termos ambientais, sociais ou econômicos. A economia global embasada pelas globalizações financeiras e produtivas juntamente com inovações tecnocientificas, causaram mudanças, precarizando e deteriorando as antigas relações de trabalho (COELHO; GODOY, 2011).

Neste contexto, um fenômeno ganha cada vez mais espaço, a chamada ES, que possui centralidade na inclusão socioeconômica, na autogestão, na equidade e na solidariedade. (GANDOLFI et. al., 2009; SILVA, 2012; SANTOS; VIEIRA; BORINELLI, 2013). O conceito de ES surgiu na França com o intuito de suprir a emergência e proliferação de inciativas e práticas socioeconômicas diversas, que assumiam formas associativas e procuravam responder a certas problemáticas locais (FRANÇA FILHO, 2003).

\section{Organizadores:}

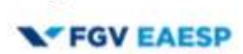

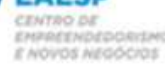

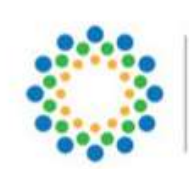

ANEGEPE

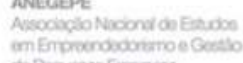
die Proveres Errortas
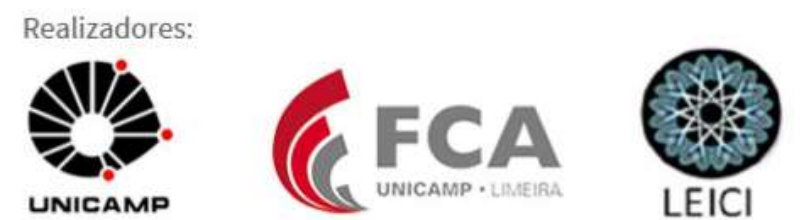
Segundo Coelho e Godoy (2011), as iniciativas da ES invertem os princípios da economia tradicional de acumulação de riquezas, passando a ser uma forma de luta política para a instituição de uma nova relação com a economia, tratando-se de um movimento complexo com dimensões econômica, política e social. Além disso, segundo Gandolfi et. al. (2009), a diferença entre economia de mercado e ES se dá devido ao fato de que enquanto uma há separação entre oferta e demanda, na outra a oferta ou serviços prestados existe apenas para suprir as necessidades ou demandas reais vividas localmente pelas populações.

Segundo Dacheux e Goujon (2011) a ES busca colocar o ser humano no centro da economia. Esses empreendimentos visam substituir a cultura do individualismo e competição, rompendo assim as relações de produção capitalistas (ARCOVERDE et. al., 2015), por outra de solidariedade e cooperação, requerendo para isso um desafio de lutar contra a hegemonia e a racionalidade do mercado (CARVALHO et. al., 2014). Desta forma, os EES constituem organizações que atuam em um campo de atividades articuladas com outras experiências em torno de um amplo movimento social. Atuam no mercado sem se submeter à busca do lucro máximo, sendo este, apenas uma forma de medir a eficiência de suas atividades e uma maneira de reinvestir em si mesmo, renovando-se e expandindo-se.

Para Lemaître e Helmsing (2012) a ES constitui, atualmente, o "coração" dos debates econômicos e sociais. Este fenômeno socioeconômico é uma área em concepção e desenvolvimento seja nas suas práticas como em suas composições teóricas (RANGEL; MANOLESCU, 2012). Segundo Coelho e Godoy (2011), em 2003 a ES se consolida, tornando política pública deliberada no âmbito do Ministério do Trabalho e Emprego (MTE), por meio da criação da Secretaria Nacional de Economia Solidária (Senaes).

Gutberlet (2015) relata que o movimento da ES vem ganhando destaque no Brasil por meio de maiores espaços políticos e pelo reconhecimento dos governos locais. Em 2007 existiam cerca de 21.859 EES no país, destes $18 \%$ se encontram na Região Sudeste. Em Minas Gerais essa representação chegava aos 5,7\%, cerca de 1236 empreendimentos. Os principais motivos listados para a criação dos EES são: alternativa ao desemprego (46\%), complemento da renda dos sócios (44\%) e obtenção de ganhos (36\%), além da possibilidade de gestão coletiva de atividade $(27 \%)$ e condição a crédito (9\%). (BRASIL, 2009)

Assim, a ES passa ser representativa no Brasil, sendo grande parte dos EES cooperativas e associações. As experiências cooperativistas surgem em resposta ao desemprego e a marginalização da sociedade mais fragilizada, oferecendo uma solução aos trabalhadores que não conseguem se encaixar nesse sistema de trabalho imposto pelo capitalismo.

\subsection{Cooperativismo}

A ES assemelha-se as primeiras experiências cooperativistas. A forma típica das organizações coletivas de trabalho é a cooperativa, onde os meios de produção são oriundos das mãos dos trabalhadores e a gestão dessas organizações é feita democraticamente entre eles

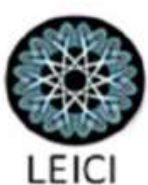


(LEMES, 2008). No Brasil, a maioria dos empreendimentos caracterizados dessa forma, estão na ES, com destaque para as associações/cooperativas populares (COELHO; GODOY, 2011).

Segundo Ramos (2011), o cooperativismo nasce no contexto do capitalismo industrial como reação ao empobrecimento dos artesões provocado pela introdução das máquinas e a organização fabril da produção que surgia durante a Revolução Industrial. Na passagem para século XX essas cooperativas que antes se caracterizavam como de consumo passam a se organizar com enfoque no trabalho e na produção industrial. Segundo o autor, as mudanças estruturais fragilizaram o modelo tradicional de relação capitalista de trabalho nas décadas de 1980/90. A informalidade e a precarização das relações formais se tornaram tendências em um contexto de desemprego, levando milhares de trabalhadores a se sujeitar a ocupações em que seus direitos são renunciados, para que consigam garantir a sobrevivência.

De acordo com Ramos (2011), no Brasil as cooperativas de trabalho só começaram a se fortalecer em meados de 1980, antes disso, apenas experiências com cooperativas de crédito, habitacionais e agrícolas existiam. Isso se deve ao fim do período militar, a adoção de medidas neoliberais e as mudanças resultantes do processo de reestruturação produtiva nas empresas. Segundo Coelho e Godoy (2011), a partir dos anos 1990, a ES torna-se um movimento pela inclusão no mercado de trabalho, diretamente ligada a crise econômica que assombrava a época e a exclusão social e suas consequências, tais como o desemprego, a marginalidade, a precarização e a informalidade.

Para Silva (2012), os EES buscam o desenvolvimento local no que refere aos aspectos econômicos e sociais, como resposta a tendência de aumento do rendimento do trabalho associado. A valorização do trabalho cooperado permite o desenvolvimento de um ambiente onde todos podem competir em condições iguais, podendo contribuir para a reconstrução de economias desestruturadas e/ou arruinadas.

Essa possibilidade de igualdade de condições competitivas não remete somente a aspectos econômicos, mas também a questões sociais e culturais devido à importância da inclusão social e profissional dos trabalhadores cooperados, representada principalmente pelo resgate da cidadania.

\subsection{A importância da inclusão social e profissional por meio das cooperativas de coleta seletiva}

No Brasil, a partir da década de 1990 surgiram alternativas para fortalecer os catadores e deixá-los mais independentes. Uma dessas alternativas foi a organização em cooperativas. Isso só foi possível em razão de políticas e ações de gerenciamento de resíduos sólidos, com o apoio do setor público e privado. A possibilidade da organização desses catadores se torna uma solução de saída da situação de exploração. Assim, a estruturação de cooperativas visa romper algumas barreiras existentes na cadeia de separação e comercialização de resíduos, visando a melhoria nas condições de vida e trabalho dos catadores (IPESA, 2013). Unidos, os catadores

\section{Organizadores:}
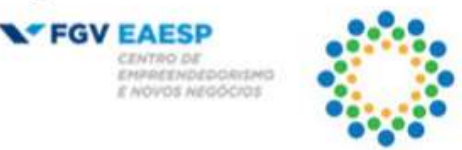
ANECOEPE

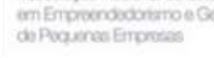
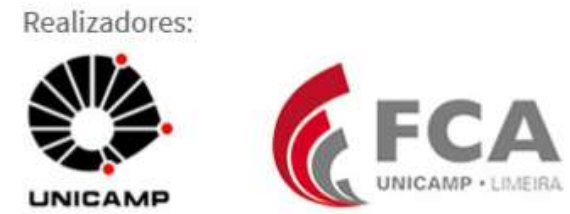

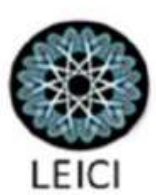


se fortalecem e obtém mais poder de barganha ao negociar seus produtos com sucateiros e indústrias do segmento.

Segundo o IPEA (2016), a maior eficácia do ponto de vista da inclusão dos catadores é a contratação formal pelas cooperativas para que atuem na coleta seletiva regular, aumentando de significativamente a renda do catador e fortalecendo a inclusão social. Para as cooperativas, a contratação formal e o aumento da renda geram como efeitos positivos incentivos para a estabilização jurídica, contábil e financeira, além da necessidade de organização e planejamento, abrindo possibilidade para modalidades de investimentos e crédito.

Outro ponto positivo das cooperativas de coleta seletiva evidenciado pelo IPEA (2016) são os ganhos ambientais e econômicos obtidos pelas prefeituras, ou seja além do ganho ambiental mais evidente (reciclar no lugar de descartar) os contratos com as cooperativas têm custado menos ao poder público do que se gasta no serviço de coleta de resíduos sólidos tradicionais, feito por grandes empresas de coleta de lixo. Por fim, a coleta seletiva formal retira o catador da "invisibilidade" e fortalece os vínculos e a integração sociais por meio da atividade educadora desempenhada.

A atuação dentro das cooperativas se torna uma ferramenta de inserção social, estabelecendo para os catadores seus deveres como profissionais e conquistando direitos como emprego, renda, respeito e uma vida mais digna (IPESA, 2013). Assim, a ES passa a ser uma nova dinâmica para o enfrentamento das desigualdades socioeconômicas, sob a crença de uma sociedade mais igualitária, justa e digna. Se destaca como um instrumento de inclusão social e resgate da cidadania (RANGEL; MANOLESCU, 2012).

Para Borges; Scholz e Rosa (2014), a formação do sujeito enquanto identidade psicológica deve ser entendida como ligada a expressividade do trabalho em sua vida, uma vez que o papel social do trabalhador se destaca diante da importância dada ao trabalho na sociedade ocidental. Pertencer ao mundo do trabalho confere valor social e moral aos indivíduos qualificando-os como "normais" e pertencentes ao modo de ser dos pares tidos como iguais, ou seja, sua identidade social. Segundo Carvalho et. al (2014) a participação em cooperativas é uma forma de alternativa ao desemprego e de reconhecimento social, uma vez que há a possibilidade do cooperado ser visto como trabalhador e não um desempregado.

Segundo Carvalho; Freitas e Vilas Boas (2013) é necessário conhecimento, a aceitação e a incorporação dos valores de trabalho preconizados pela ES para que haja a mudança da postura competitiva para uma postura cooperativista. Segundo Oliveira et. al (2012), as cooperativas e associações vem se mostrando como cumpridoras de um papel social importante, sendo geridas por princípios de solidariedade, cooperação, mutualismo e autogestão. Assim, muitos catadores de materiais recicláveis estão se organizando formalmente em cooperativas no sentido de se fortalecerem na cadeia produtiva da reciclagem.

Dentre os estudos utilizados para esta pesquisa, alguns se destacam por fazerem uma análise da ES de forma geral, além de considerarem como uma alternativa para o trabalho e renda, aumentando o consumo e a qualidade de vida dos participantes dos EES (ARCOVERDE,
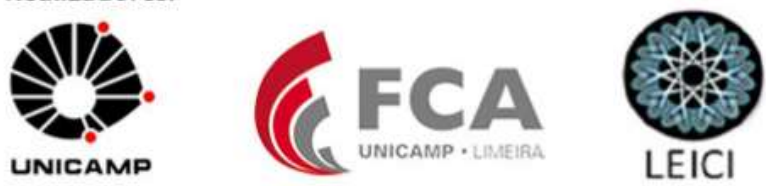
2015; GANDOLFI et. al., 2009; VIEIRA, PAULA, 2013). Outro aspecto encontrado nesses estudos é que evidenciam uma maior participação política e social dos trabalhadores na comunidade onde estão inseridos (ARCOVERDE, 2015; SILVA, 2012.), assim como a satisfação pessoal ou do grupo pela a inserção no empreendimento (ARCOVERDE, 2015). O maior acesso a capacitação em cursos de formação e aperfeiçoamento também é considerado fruto dos empreendimentos. (SILVA, 2012).

Já os estudos que destacam as cooperativas de reciclagem como prática econômica solidária, trazem como resultados, a ressignificação da identidade (BORGES; SCHOLZ; ROSA, 2014) e a busca pelo prazer e pela realização pessoal (CARVALHO; FREITAS; VILAS BOAS, 2013). Os cooperados têm como prioridade os valores relacionados à estabilidade (CARVALHO; FREITAS; VILAS BOAS, 2013). Outro fator positivo é que a inserção nesses empreendimentos incentiva a interação social; a experiência da reflexão cívica e solidária, de preocupação com o próximo e com o todo, ou seja noções de direito (COELHO; GODOY, 2011; BORGES; SCHOLZ; ROSA, 2014); e o desenvolvimento de competências gerenciais, por meio da aprendizagem, na práxis, de noções de administração (COELHO; GODOY, 2011). Ou seja, ocorre aprendizado em termos de mudança de comportamento nos níveis individual, interacional e organizacional (BORGES; SCHOLZ; ROSA, 2014).

Assim, a ES tem um papel crucial na vida dos indivíduos que a utilizam. Além de afetar socioeconomicamente a vida dessas pessoas, também é de grande importância para a construção moral e psicológica, visto as melhorias subjetivas que consegue realizar.

\section{Metodologia}

O presente estudo caracteriza-se como uma pesquisa qualitativa, sendo um estudo de casos múltiplos. Segundo Sampieri, Collado e Lucio (2013), o enfoque qualitativo busca compreender a concepção dos participantes sobre fenômenos que os rodeiam, penetrar em suas experiências, pontos de vistas, opiniões e significados. Já o estudo de caso é usado quando se deseja entender um fenômeno no mundo real e assumir que para isso envolva pertinentes condições contextuais, ou seja, os limites entre o fenômeno e o contexto podem ser claramente evidentes (YIN, 2015).

A pesquisa tem caráter exploratório, que segundo Sampieri, Collado e Lucio (2013) serve para familiarizar com o fenômeno ao mesmo tempo que busca obter informações para a possibilidade de se realizar pesquisas mais completas relacionadas a um contexto particular. Quanto à natureza, trata-se de uma pesquisa básica pois visa obter conhecimentos novos de natureza teórica, que em momento imediato possui pouco impacto direto sobre ação, desempenho ou decisões políticas (COOPER; SCHINDLER, 2011).

Para a coleta de dados foram desenvolvidos três roteiros semiestruturados, visando levantar informações sobre três pontos de vista distintos: gestores, participantes e exparticipantes. Foram visitados 5 empreendimentos que realizam a coleta, o preparo e a comercialização do material reciclável em Uberlândia - MG. O intuito na coleta de dados era
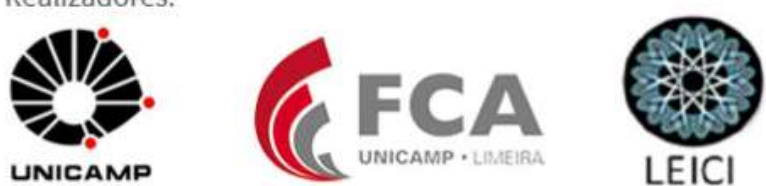
que fosse realizado entrevistas com o gestor, 2 participantes e 2 ex-participantes de cada uma das organizações, entretanto, particularmente em 3 empreendimentos foi encontrado apenas um ex-participantes que concordou em participar da pesquisa, assim, foram realizadas (ao todo) 18 entrevistas no período de janeiro/2017 a fevereiro/2018. Os dados foram analisados por meio da técnica de análise de conteúdo, que objetiva filtrar a classificação sistemática e a contagem de extensas informações colhidas, transformando-as em um texto curto e objetivo com as características representativas do que se pretende descobrir (BARDIN, 2011).

Para a análise de conteúdo foram estabelecidas categorias construídas a priori, ou seja, a partir do referencial teórico, apresentadas no Quadro 1.

Quadro 1: Categorias de Análise

\begin{tabular}{|c|c|}
\hline CATEGORIA & SUBCATEGORIA \\
\hline \multirow{2}{*}{ Geração de Emprego } & Inserção nos Empreendimentos \\
\cline { 2 - 2 } Ramos (2011); Arcoverde (2015); Gandolfi et. al. & Realização Pessoal e Profissional \\
\cline { 2 - 2 } (2009); Vieira; Paula (2013); Carvalho; Freitas; Vilas & Qualidade de Vida \\
\cline { 2 - 2 } Boas (2013); Costa e Cargin (2012). & Ambiente de Trabalho \\
\cline { 2 - 2 } Relações Sociais & Cidadania \\
\hline Coelho; Godoy (2011). & Inclusão Social \\
\cline { 2 - 2 } Capacitação Profissional e Aperfeiçoamento \\
Silva (2012); Coelho; Godoy (2011). & - \\
\hline Geração de Renda & \\
\hline Ramos (2011); Arcoverde (2015); Gandolfi et. al. & \\
(2009); Vieira; Paula (2013); Carvalho; Freitas; Vilas \\
Boas (2013).
\end{tabular}

Fonte: Elaborado pelos autores

\section{Resultados}

Este estudo procurou identificar como os EES impactam na trajetória profissional de seus participantes. Foram entrevistados um total de 18 pessoas entre participantes, gestores e ex-participantes. Destes 9 eram mulheres com faixa etária entre 20 e 67 anos, já os homens possuem faixa etária entre 23 e 53 anos. Para melhor compreensão foi criada a legenda apresentada no Quadro 2 a fim de identificar os entrevistados. Nos tópicos seguintes, encontram-se os principais resultados da pesquisa divididos em categorias de análise. 
Quadro 2: Legenda para identificação dos entrevistados

\begin{tabular}{|l|l|l|l|}
\hline Organização & Gestor & Participantes & Ex - Participantes \\
\hline O1 & G1 & P1a, P1b & H1a, H1b \\
\hline O2 & G2 & P2a, P2b & H2a, H2b \\
\hline O3 & G3 & P3a, P3b & H3a \\
\hline O4 & G4 & P4a, P4b & H4a \\
\hline O5 & G5 & P5a, P5b & H5a \\
\hline
\end{tabular}

Fonte: Elaborado pelos autores

\subsection{Geração de Emprego}

\subsubsection{Inserção nos Empreendimentos}

Geralmente, o primeiro contato com a reciclagem se dá devido à falta de oportunidades no mercado de trabalho formal, sendo que os principais problemas enfrentados pelos participantes têm relação direta com o período pós-gestação, no caso das mulheres, em que não conseguem conciliar trabalho e cuidado com os filhos, além de pessoas com lesões físicas ocorridas em acidentes de trabalho (afastamento pelo INSS) e de modo geral, com a baixa escolaridade. Um caso especial de êxodo rural chama atenção, onde o participante vindo da zona rural não conseguiu emprego, visto a falta de preparo para o mercado de trabalho urbano.

A inserção nos empreendimentos ocorre também por influência e convite de parentes e amigos, geralmente fundadores ou membros antigos das associações/cooperativas. A estabilidade de trabalho e a maior renumeração do que se estivessem no mercado (devido à falta de capacitação) e as melhores condições de trabalho (em comparação com o trabalho de catador nas ruas) também são motivos citados pelos entrevistados para a inserção nesses empreendimentos e por fim, como complementação de renda ou seja, um "bico".

Esses resultados vão ao encontro de pesquisas que mostram que o desemprego entre as mulheres é um fator de inserção nos empreendimentos (RAMOS, 2011) e que a estabilidade e a renda é um fator de atratividade para os participantes (RAMOS, 2011; CARVALHO; FREITAS; VILAS BOAS, 2013).

\subsubsection{Realização Pessoal e Profissional}

A permanência nos empreendimentos tem relação direta com o quão os participantes se sentem realizados pessoal e profissionalmente no trabalho que realizam. Desta forma, a análise dessa categoria levou em questão duas principais abordagens: participantes e gestores que estão ativamente na associação/cooperativa e ex-participantes que optaram pela saída.

O sentimento de estarem trabalhando para si mesmos, a flexibilidade de horários e a não existência de um "patrão" foram citados por quatro entrevistados (H2b, G1, P2a e P5b). Os participantes e gestores também se sentem como se trabalhasse em família, sempre evidenciando o bom relacionamento entre eles. $\mathrm{O}$ rendimento ganhado a partir do trabalho

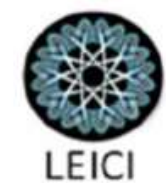


também é um fator de satisfação em permanecer nos EES. Demostram acreditar na capacidade de crescimento da associação/cooperativa evidenciando o prazer de trabalhar com reciclável, possuindo consciência da importância do trabalho que realizam.

Alguns participantes (P5b, P3a, P3b e P1b) demonstraram o interesse em sair dos empreendimentos, relatando que a expectativa em ter uma carteira assinada é o principal motivo. Analisando as entrevistas com os ex-participantes notou-se que a inexistência de um horizonte de crescimento dentro do empreendimento é um dos motivos relatados para a saída. Estes almejam crescer em uma empresa e ter cargos diferenciados o que não era enxergado nos EES. Problemas de saúde (principalmente físicos, devido ao esforço) e o conflito de valores/interesses também gera a saída dos participantes, que discordam do modo como é gerenciado os empreendimentos. Por fim, a busca de uma estabilidade financeira é citado como um dos motivos para o desligamento. Dois casos especiais chamam atenção, onde um exparticipante e um participante demonstram características empreendedoras, montando seus próprios negócios:

P4b: “(...) eu já tenho um projeto de formalizar uma...uma empresa de pimentas, temperos e pimentas ao qual eu já tenho até... já estou montando toda a estrutura né, para... porque mexer com pimentas também porquê...porque mexer é área que eu também amo muito..."

H4a: “Aí eu sai mesmo porque eu fui montar minha oficina né. (...) Eu não tinha acabado de montar, porque eu não tinha de onde tirar e como eu tava trabalhando lá eu fui juntando dinheiro que eu ganhava lá pra abrir a oficina”.

Estes resultados apontam semelhança com os resultados de outras pesquisas, que indicaram a autonomia em relação as decisões do trabalho, flexibilidade e o fato de não terem pressão sobre o trabalho (CARVALHO; FREITAS; VILAS BOAS, 2013) como fatores de influência para a permanência no empreendimento. Carvalho et. al (2014) mostram que os participantes apresentam em ordem de prioridades a realização com o trabalho (prazeroso, significativo e gratificante) seguido de reconhecimento e satisfação pessoal. O sentimento de contribuição com o meio ambiente também é evidenciado (CARVALHO; FREITAS; VILAS BOAS, 2013; COELHO E GODOY, 2011; BORGES, SCHOLZ; ROSA, 2014). É possível encontrar relação com os estudos que evidenciam a ideia de revolução entre as relações de patrão e empregado, sendo a cooperativa um marco para a valorização do indivíduo e o trabalho (COELHO; GODOY, 2011; BORGES; SCHOLZ; ROSA, 2014).

\subsubsection{Qualidade de vida}

O aumento de renda e consequentemente o aumento do poder de compra são os principais impactos na qualidade de vida, ocasionada pela entrada nos EES. Quatro participantes e um ex-participante relataram que conseguiram adquirir bens a partir do aumento de renda, o que pode ser ilustrado pelo relato do P1b a seguir:

“Condição para estudar que eu não tinha condição, paguei... pagava quase 800 reais por mês de escola, comecei a estudar com nada... não tinha escolaridade quando entrei

\section{Organizadores:}
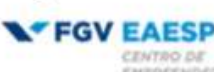

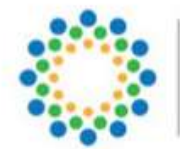

ANEOEPE

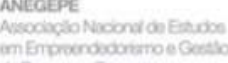
is Proveres Erroming

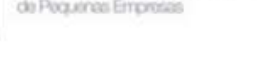
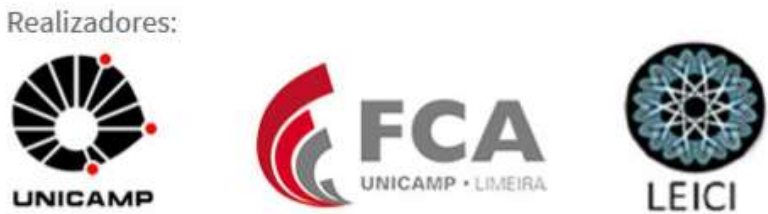
aqui, sabe? Tudo foi financiado por aqui. Isso aqui que me financiou... eee... carro, casa, moto, tudo foi tirado daqui de dentro." (P1b)

Esses resultados se mostram semelhantes aos encontrados em outras pesquisas que indica o aumento de renda (RAMOS, 2011; ARCOVERDE, 2015; VIEIRA E PAULA, 2013; COELHO; GODOY, 2011; CARVALHO ET AL, 2014) e do poder de compra (RAMOS, 2011; ARCOVERDE, 2015; COELHO; GODOY, 2011) como principais impactos na qualidade de vida dos participantes.

\subsubsection{Ambiente de Trabalho}

A segurança no ambiente de trabalho, principalmente no setor abordado, é algo de extrema importância para a integridade do trabalhador. Um dos pontos comuns encontrados nos empreendimentos analisados é que há fornecimento de EPIs (por meio de empresas privadas que doam esses equipamentos), porém existe muita resistência de uso por parte dos participantes que relatam que os EPIs fornecidos não se adequam ao tipo de trabalho que fazem. Em um dos empreendimentos ocorre, uma vez por semana, um mutirão para evitar a propagação da dengue e seus gestores procuram trazer agentes de saúde para vacinar os membros contra dengue e febre-amarela.

Uma das principais queixas refere-se a infraestrutura física, que se encontra precária, o que corrobora com o estudo de Costa e Cargin (2012). Os galpões fornecidos pela prefeitura (onde todas as associações/cooperativas conveniadas estão instaladas) não atendem a demanda de espaço, havendo a necessidade de ampliação. Há necessidade de máquinas para que possam aumentar a produção e vender produtos de maior valor agregado como o "grão da PET". Também não existe as condições mínimas que atendem as necessidades dos trabalhadores como demonstrado na fala do G1: “(...) Assim, a maioria do pessoal trabalha no sol entendeu? Não tem lugar fechado, a gente não tem o refeitório pro pessoal fazer as refeições, o banheiro é precário."

Uma das variáveis que impacta diretamente no ambiente de trabalho é a relação interpessoal dos trabalhadores. Nos EES analisados a relação relatada evidencia uma convivência quase harmônica, com poucos conflitos. Os participantes fazem uso de uma comparação com a família para descrever a relação entre eles. O G2 procura trabalhar questões de motivação dentro da associação, procurando trazer ações (confraternizações de aniversariantes) que faça com que os associados se sintam valorizados e reconhecidos pelo trabalho que fazem.

Ramos (2011) mostrou que no seu estudo sobre valores na ES os laços de reciprocidade, apesar de aparecem na pesquisa, não representaram muita importância. Já Costa e Cargin (2012), de forma semelhante à presente pesquisa, indicaram que por meio desses laços, os participantes vão além do trabalho em si, mostrando preocupações com outras esferas de relação como bem-estar/mal estar, relações de poder e interpessoais. 


\subsection{Relações Sociais}

\subsubsection{Cidadania}

Uma das questões investigadas envolve a percepção dos participantes sobre os seus direitos e deveres. Em relação a própria cooperativa/associação eles demonstram ter conhecimento sobre os direitos e deveres como membros, conseguem a partir das práticas da autogestão expor suas ideias e se posicionar melhor a partir das suas noções de direito. A questão do INSS é tratada de forma opcional e os gestores procuram conscientizar sobre a importância de se pagar e os benefícios que ele pode trazer, mas deixando a decisão final para o participante visto que não é obrigatório por lei (no caso da associação). Mas apenas dois participantes (P2b e P4b) declararam efetuar o pagamento do INSS.

Coelho e Godoy (2011) mostram em sua pesquisa que as práticas de autogestão facilitam o reconhecimento dos direitos e deveres por parte do cooperado ajudando no seu desenvolvimento crítico e argumentativo concedendo a este noções de direitos. Já Ramos (2011) encontrou que apesar da cidadania aparecer em seus estudos sobre valores na ES demonstra pouco significado para os participantes.

\subsubsection{Inclusão Social}

A inclusão social envolve, entre outras coisas, ter acesso a serviços básicos de maneira simples e fácil. Apesar de que, ao longo do tempo, parcerias com a prefeitura e a UFU terem fornecidos o acesso a esses serviços, hoje em dia, encontram-se de forma carente. Houve um afastamento por parte das instituições e com isso, os participantes sentem dificuldades para conseguir esses serviços.

Foi possível identificar, na $\mathrm{O} 2$ e $\mathrm{O} 3$, intenções e ações internas que pudesse impactar a vida dos participantes de maneira a possibilitar maior inclusão social. Houve relatos sobre a busca de parcerias para possibilitar o maior acesso a bens (consórcio para adquirir veículos) e a convênios de saúde (odontológico e médico). Também existem situações onde a atuação dos empreendimentos contribuíram para a reabilitação de ex-dependentes químicos e exalcoólatras, onde o trabalho com material reciclável foi o fator de transformação.

P3a: "Eu (...) sou um ex-dependente químico e aqui me ajudou muito a minha reabilitação sabe eu me dei........mas estou ai firme. Fui dependendo do meu serviço ou não, o que fiz no passado isso aqui pra mim é uma maravilha, trabalhar e ter um sustento digno não precisar ir na rua e roubar, esses trens aí."

A participação privada no auxílio nas cooperativas/associações é maior que a atuação pública, sendo as empresas de médio e grande porte como as principais financiadoras de suas atividades. Um dos empreendimentos demonstrou possuir grande representatividade no grupo empresarial da cidade e dos movimentos sociais vinculados aos catadores.

A principal forma de benefício adquirido a partir do governo federal é o Bolsa Catador. Trata-se de uma gratificação em dinheiro para as associações/cooperativas que demonstrarem de forma transparente e com bons resultados suas atividades. Essa quantia, normalmente, é

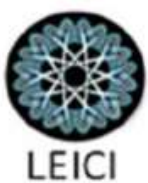


repassado aos associados em forma de bonificação. Apenas um dos empreendimentos recebia esse benefício, pois de forma geral, as associações e cooperativas demonstram dificuldades de gestão e não conseguem todos os documentos necessários para receber o benefício.

Os estudos de Ramoms (2011) e Coelho e Godoy (2011) também indicaram que a criação deste tipo de empreendimento apresenta cunho social, sofrendo influências da prefeitura e órgãos de apoio para a geração de ganhos sociais.

\subsection{Capacitação profissional e aperfeiçoamento}

A análise desta categoria demonstra singularidades quando é abordada nesse setor. Primeiramente, é representativa a faixa de pessoas que não concluíram o ensino fundamental e médio. Durante as entrevistas, 12 pessoas relataram que não concluíram o ensino fundamental. Uma entrevistada em especial nunca chegou sequer a frequentar a escola. O restante dos entrevistados diz ter concluído o ensino médio, com destaque para 4 pessoas que possuem curso superior. A capacitação dos gestores também demonstra impactar sobre os empreendimentos. Os que possuem curso superior, sendo um formado em Administração de Empresas e outro em Direito e Enfermagem, procuram trabalhar os conceitos que aprenderam e vivenciaram no mercado para melhorar o desempenho dos EES e a qualidade de vida dos participantes.

Existe bastante oferta de cursos de capacitação profissional através de iniciativas como a UFU, o SEBRAE, ACIUB e empresas privadas. Porém, a receptividade por parte dos associados/cooperados é muito baixa. Poucos frequentam esses cursos, alguns começam e não terminam. Um dos motivos alegados para não se capacitarem é a falta de tempo, já que dependem do serviço para sobreviver não podendo deixar o trabalho para estudar. Eles também não se sentem à vontade no ambiente escolar, dizem não se encaixar, possuindo baixa autoestima em relação a aparência e ao modo de se relacionar e os mais velhos relataram que com a idade avançada, já não possuem "cabeça" para os estudos. Quanto a vontade de estudar, 5 gestores, um participante e um ex-participante demonstraram interesse. Um dos gestores pretende construir uma sala de aula no próprio empreendimento a fim de solucionar esses problemas evidenciados pela falta de capacitação e incentivar os participantes a concluírem seus estudos.

Os resultados encontrados apresentam semelhanças aos encontrados por Ramos (2011) e Silva (2012) que indicam que há qualificação por parte dos participantes, porém este estudo pode descobrir que apesar do acesso a esses cursos de qualificação existe uma resistência por parte dos participantes em continuar seus estudos. Outras pesquisas também apontaram a baixa escolaridade entre os participantes (SILVA, 2012; COELHO; GODOY, 2011).

\subsection{Geração de renda}

A perspectiva de remuneração demonstra ser satisfatória, onde grande parte dos participantes relataram que ganham muito mais do que se estivessem no mercado trabalhando

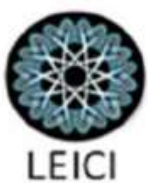


com carteira assinada, o que também e encontrado nas pesquisas de Gandolfi et. al. (2009), Coelho e Godoy (2011) e Carvalho et. al. (2014).

Apenas alguns participantes (H5a, H3a, P5b, P3b) reclamaram que sofrem com baixas remunerações, normalmente vinculados a produção individual. Uma grande diferença notada entre os empreendimentos estudados é que eles trabalham com distintas formas de produção e remuneração. Dois empreendimentos utilizam da clássica forma de produção e renumeração da ES baseada na produção coletiva e na divisão igualitária dos rendimentos, conforme identificado no estudo de Silva (2012) enquanto os outros três baseiam-se em versões adaptadas do sistema capitalista de produção, utilizando da produção e remuneração individual ou em equipe (geralmente duplas).

\subsection{Gestão organizacional}

Os EES mantêm um relacionamento complicado e de dependência com a prefeitura. Esta não consegue fazer de modo eficiente a coleta seletiva, por meio da terceirização. Os catadores lutam pela oportunidade de fazerem essa coleta, visto que detém de conhecimento de quais materiais são recicláveis (evitando retrabalhos, pois muitos materiais vem misturados) e de que realizando esse trabalho os EES poderiam se desenvolver economicamente melhor. Também existem grandes dificuldades quando o assunto é sucessão de liderança. Não existem muitos membros dispostos a assumir cargos de liderança comprometendo a longo prazo a gestão. Normalmente a eleição ocorre com chapa única, sendo que os eleitos ficam mais de um mandado no cargo não havendo o revezamento de gestões, pois são reeleitos sem concorrência.

Há o interesse em atingir o catador de rua, de forma que ele repasse o material para que o empreendimento possa revender. Uma das dificuldades que está impedindo que essa expansão ocorra é a falta de capital de giro já que esses catadores de rua recebem à vista. Um desses empreendimentos já engatinha nessa expansão, com alguns catadores de rua como fornecedores e além disso, possui filiais em outro estado. Já o recrutamento e seleção dos novos associados e cooperados acontece de forma parecida em todos os EES analisados. Primeiramente é feita uma entrevista e um período de experiência de 3 meses. Após isso, é realizado a entrada do novo membro. Geralmente são as pessoas interessadas que procuram pela vaga ou devem ser indicados por algum membro pertencente ao empreendimento.

Coelho e Godoy (2011) apresentam em sua pesquisa as relações entre o setor público (prefeitura) e a cooperativa comentando sobre a história de formação a partir de influencias públicas. Os resultados alcançados por esta pesquisa também evidenciaram a relação (e dependência) do poder público para a execução das atividades dos empreendimentos

\section{Conclusões}

No contexto atual no qual a sociedade está inserida houve um aumento no número de pessoas que passaram a atuar como catadores de materiais recicláveis. Por meio da união desses catadores em cooperativas/associações, representações da economia solidária, conseguem se
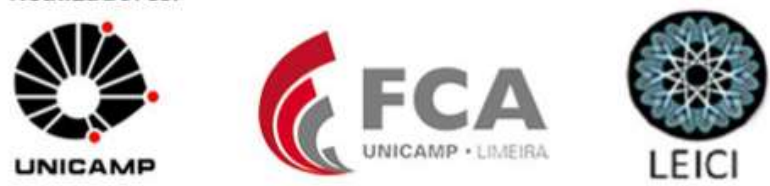
fortalecer e tornar mais independentes. Partindo destas premissas, este estudo pode identificar como os EES impactam na trajetória profissional de seus participantes. Diretamente, eles possibilitam estabilidade financeira, possibilidade de maiores ganhos, autonomia nas decisões referente ao trabalho, acesso a capacitação profissional, além da melhor infraestrutura e condições de trabalho. Indiretamente, possibilitam melhorias na qualidade de vida, consciência sobre direitos e deveres e maior acesso a benefícios sociais. Dessa forma, podemos concluir que o objetivo deste estudo foi alcançado.

Sugere-se para as iniciativas que visam ofertar cursos de capacitação aos participantes que estudem maneiras de levar a sala de aula aos empreendimentos ao invés do deslocamento destes participantes até ela, visto que a maioria dos relatos indicam que estes possuem pouca adesão devido ao deslocamento e tempo gasto até chegar ao local de estudo. Também é importante mencionar que como há grande resistência por parte dos participantes em usar os equipamentos de segurança é necessário criar internamente ações que visam aumentar o uso desses equipamentos. A maior parte das queixas evidenciadas se refere sobre a atuação do poder público. É relatado uma lacuna entre os empreendimentos e o CIEPS UFU. Assim, sugere-se que haja uma maior aproximação entre a incubadora e os EES para que ela possa atender as demandas sociais no qual esses empreendimentos possuem e carecem de forma imediata.

Para a execução deste trabalho, houve dificuldades para identificar e entrar em contato com os ex-participantes. Por fim, vale salientar que este trabalho tendo limitado a análise de 5 empreendimentos não demonstra a realidade geral do setor. Apenas apresentou uma amostra dos impactos que os EES podem ocasionar na vida de seus participantes. Para estudos futuros foi identificado a necessidade de analisar as dificuldades de sucessão e as distintas formas de produção nesses empreendimentos, o que contradiz os princípios básicos da ES.

\section{Referências}

ARCOVERDE, A. C. B. et. al. Avaliação dos impactos do trabalho no contexto de empreendimentos econômicos solidários de Pernambuco. In: Jornada Internacional de Políticas Públicas, 7., 2015, São Luís. Anais... São Luís - MA: Universidade Federal do Maranhão, ago. 2015.

BARDIN, L. Análise de Conteúdo. $2^{\mathrm{a}}$ reimp. da $1^{\mathrm{a}}$ edição de 2011. São Paulo: Edições 70, 2011.

BORGES, M. L.; SCHOLZ, R. H.; ROSA, G. F. Identidade, aprendizagem e protagonismo social: sentido do trabalho para sujeitos recicladores. Outra Economía. v. 8, n. 14, jan./ jun. 2014.

BRASIL, MINISTÉRIO DO TRABALHO E EMPREGO (MTE). Atlas da Economia Solidária no Brasil, 2005 -2007. Associação Nacional dos Trabalhadores e Empresas de Autogestão Acionária -ANTEAG (Org.). São Paulo: Todos os Bichos, 2009. 64 p. 
CARVALHO, V. D. et. al. Valores do trabalho e incubação de empreendimentos solidários: a experiência da associação terra do marolo. Psicologia \& Sociedade. v. 26, n. 2, p. 449 - 460, 2014.

CARVALHO, V. D.; FREITAS, T. A.; VILAS BOAS, E. M. Valores do trabalho em empreendimentos solidários: estudo de caso entre os membros de uma cooperativa de coleta $\mathrm{e}$ reciclagem de lixo. Cadernos Gestão Social. v. 4, n. 1, p. 135-150, jan./jun. 2013.

COELHO, D. B.; GODOY, A. S. De catadores de rua a recicladores cooperados: um estudo de caso sobre empreendimentos solidários. Revista de Administração Pública. Rio de Janeiro, v. 45, n. 3, p. 721-749, mai./jun. 2011.

COOPER, D. R.; SCHINDLER, P. S. Métodos de pesquisa em Administração. 10 ed. Tradução de Iuri Duquia Abreu. Porto Alegre: Bookman, 2011. 762 p.

COSTA, N. M.; CARGNIN, T. M. Antes e depois do galpão: refletindo a partir de formadores/educadores nas unidades de triagem. Revista CIPPUS - UNILASALLE, v. 1, n. 2, p. 147-157, nov. 2012.

DACHEUX, E.; GOUJON, D. The solidarity economy: an alternative development strategy? International Social Science Journal, v. 62, p. 205 -215, mar./jun. 2011.

FRANÇA FILHO, G. C. A temática da economia solidária e suas implicações originais para o campo dos estudos organizacionais. Revista de Administração Pública. Rio de Janeiro, v. 37, n. 1, jan. / fev. p. $11-31.2003$.

GANDOLFI, P. E. et. al. Empreendimentos solidários como alternativa para a geração de trabalho e renda: a experiência da INES/UFU. Em Extensão. Uberlândia, v.8, n.1, p. 159173, jan./jul. 2009.

GUTBERLET, J. Cooperative urban mining in Brazil: collective practices in seletive household waste collection and recycling. Waste Management, v. 45, p. 22-31, 2015.

GUTBERLET, J. Informal and cooperative recycling as a poverty eradication strategy. Geography Compass, v. 6, n. 1, p. 19 - 34, 2012.

INSTITUTO DE PESQUISA ECONÔMICA APLICADA (IPEA). Catadores de materiais recicláveis: um encontro nacional. Bruna C. J. Pereira; Fernanda L. Goes. (Org.) Rio de Janeiro: Ipea, 2016. 558 p.

INSTITUTO DE PROJETOS E PESQUISAS SOCIOAMBIENTAIS (IPESA). Do lixo à cidadania: guia para a formação de cooperativas de catadores de materiais recicláveis. Julio Ruffin Pinhel (org.). São Paulo: Petrópolis, 2013. 239 p. 
LEMAÎTRE, A.; HELMSING, A.H.J. Solidarity Economy in Brazil: movimento, discourse and practice analysis through a polanyian understanding of the economy. Journal of International Development, v. 24, p. 745-762, 2012.

LEMES, F. R. M. A inserção da economia solidária no mercado: contradições e possibilidades. Outra Economía. v. 2, n. 2, p. 52-57, jan./jun. 2008.

OLIVEIRA, M. C. et. al. Valores de trabalho de catadores de materiais recicláveis: expectativas com o trabalho cooperado. Revista Paranaense de Desenvolvimento. Curitiba, n. 122, p. 201-220, jan./jun. 2012.

RAMOS, A. T. A. A organização feminina em empreendimentos solidários: uma alternativa de inclusão ao mercado de trabalho. In: Simpósio Gênero e Políticas Públicas, 2., 2011, Londrina. Anais... Londrina, PR: Universidade Federal de Londrina. ago./set. 2011.

RANGEL, R. R.; MANOLESCU, F. M. K. Economia solidária pela perspectiva históricoteórica. Educação, Gestão e Sociedade. a. 2, n. 8, p. 1-30, dez. 2012.

SAMPIERI, R. H.; COLLADO, C. F.; LUCIO, M. P. B. Metodologia de Pesquisa. Tradução de Daisy Vaz de Moraes. 5. ed. Porto Alegre: Penso, 2013. 624 p.

SANTOS, L. M. L.; VIEIRA, S. F. A.; BORINELLI, B. Economia solidária e estratégia: entre princípios e pragmatismo. Revista Ibero-Americana de Estratégia, São Paulo, v.12, n.4, out. /dez. p. $261-278.2013$.

TREMBLAY, C.; GUTBERLET, J. Empowerment through participation: assessing the voices of leaders from recycling cooperatives in São Paulo, Brazil. Community Development Journal, v. 47, n. 2 1, p. 282-302, abr. 2012.

SILVA, L. T. Concepção de trabalho utilizado nos empreendimentos solidários: experiência do centro de economia solidária da Bahia. Revista de Gestão, Finanças e Contabilidade, UNEB, Salvador, v. 2, n. 2, p. 61-67, maio/ago., 2012

VIEIRA, R. M.; PAULA, C. S. Perfil dos empreendimentos solidários no Brasil e no estado de Mato Grosso do Sul. In: Seminário Internacional de Integração e Desenvolvimento Regional, 1. 2013, Ponta Porã - MS. Anais... Ponta Porã, MS: Universidade Estadual do Mato Grosso do Sul. set. 2013.

YIN, R. K. Estudo de Caso: planejamento e métodos. 5. ed. Tradução de Cristhian Matheus Herrera. São Paulo: Bookman, 2015. 289 p. 